\title{
Diabetes and Atherosclerosis - The Role of Insulin
}

\author{
R. W. Stout \\ Department of Geriatric Medicine, The Queen's University of Belfast, Belfast, Northern Ireland
}

\section{Diabetes and Cardiovascular Disease}

Vascular disease is one of the commonest, as well as one of the most serious chronic complications of diabetes. Diabetics are susceptible to disease of both the large muscular arteries, particularly those supplying the myocardium, the brain and the lower limbs, and the capillaries, of which those in the retina and the glomerulus are the most important clinically. The capillary disease, or microangiopathy, appears to be closely related to the diabetic state, and is distinct from the macroangiopathy. It will not be considered further here. The disease of the large vessels is atherosclerosis, which in diabetics, differs neither in distribution nor in morphology from atherosclerosis in non-diabetics [1].

A large number of clinical studies suggest that diabetics have an unusually high prevalence of atherosclerosis [2]. The pitfalls of describing a high prevalence of one common disease in the presence of another have been emphasised [3] and it has not been clear from retrospective clinical studies whether the relationship between diabetes and atherosclerosis is independent of the other 'risk factors' for atherosclerosis commonly found in diabetes, such as obesity, hyperlipidaemia and hypertension. This problem has recently been partly resolved by several epidemiological studies in unselected population groups.

In the Framingham study [4] diabetic men and women developed more cerebral, coronary and peripheral vascular disease than non-diabetics, the incidence of intermittent claudication being particularly high in the diabetics. The mortality rate from cardiovascular disease in the diabetics was almost three times that in the general population. The impact of diabetes on coronary heart disease was particularly strong in women [5], but the relative excess for women was confined to those who were treated with insulin. Although the mean levels of some cardiovascular risk factors were higher in diabetics than in comparable non-diabetics, the differences were not great enough to account entirely for the excess incidence of coronary heart disease in the diabetics. There appeared to be some unique effect of diabetes, especially in women, which was not explained by associated cardiovascular risk factors.

Two prevalence studies have reported an association of diabetes and vascular disease in unselected population groups. In Bedford [6], a standardised cardiovascular survey was performed in three population groups classified as normal, borderline or diabetic, on the basis of the blood sugar level two hours after $50 \mathrm{~g}$ of glucose by mouth. The frequency of cardiovascular disease was highest in the diabetic group, intermediate in the borderline group, and lowest in those with normal blood sugar levels. The trend to increasing frequency with increasing blood sugar value was greater in women, and was more marked in those aged over 50 years. In Tecumseh, Michigan [7] diabetics at every age had more vascular disease than the population as a whole. Conversely, hyperglycaemia was considerably more frequent in subjects with cardiovascular disease than in the general population. Furthermore, hyperglycaemia was an independent risk factor for coronary heart disease [8] and seemed to be at least as important as either hypertension or hypercholesterolaemia. In a group of 370 male diabetics in an industrial population followed for 10 years [9], the death rate of the diabetics was 2.6 times higher than that of matched controls, and the excess mortality was highest in the group under 45 years of age. The most striking difference was seen in the incidence of coronary heart disease which caused the deaths of nearly three times as many diabetics as non-diabetics.

Other workers have shown a high frequency of abnormal oral and intravenous glucose tolerance 
tests in subjects with ischaemic heart disease [10]. Particularly significant was the finding of hyperglycaemia in subjects with angiographically demonstrated atherosclerosis of coronary [11, 12], or peripheral $[13,14]$ arteries without occlusion or infarction. These findings are consistent with the view that hyperglycaemia is related to the arterial disease itself, rather than being a non-specific response to the stress of an acute illness.

An exception to the association of diabetes and coronary heart disease occurs in the American Pima Indians. In this population there is a low prevalence of coronary heart disease despite a very high prevalence of diabetes [15]. Another exception to the general rule occurs in growth-hormone-deficient dwarfs. In these subjects, atherosclerotic complications are few despite hyperglycaemia and hypertriglyceridaemia [16].

Thus the majority of epidemiological studies, both cross-sectional and prospective, confirm the association between diabetes and cardiovascular disease. Mild abnormalities of glucose tolerance and hyperglycaemia of insufficient degree to be classified as diabetes by conventional criteria are also associated with an increased frequency of cardiovascular disease. Hyperglycaemia is present early in the development of atherosclerosis and has a predictive value for the development of cardiovascular disease. The predictive value of hyperglycaemia seems to be independent of the effects of co-existing hypertension, hypercholesterolaemia and cigarette smoking [17]. Particularly intriguing is the relatively greater risk to which diabetic women are susceptible: diabetes is the only common disease in which the usual sex difference in the incidence of atherosclerosis is abolished.

\section{Blood Glucose}

As diabetes is a disorder whose best known characteristic is elevation of blood glucose concentration, it might be considered that this abnormality may have a causal role in the development of the large vessel complications. Epidemiological and clinical studies, however, give contradictory evidence.

The relationship of the duration and severity of diabetes to the vascular complications is unclear. The diagnosis of diabetes leads almost invariably to the institution of some form of treatment, so that it is difficult to differentiate the influence of the disease from the influence of treatment on the development of the complications. In many cases, treatment of diabetes allows the patient to survive long enough to develop the chronic complications. Furthermore, in most cases it is impossible to determine the date of onset of diabetes, particularly as glucose intolerance may be a late manifestation of a complex disorder which may have been present from birth. Frequently the presence of diabetes is discovered when the patient seeks medical assistance for some other condition, and it is clear from the many reports of a high frequency of previously undiagnosed diabetes and glucose intolerance in patients presenting with vascular disease, that atherosclerosis in many diabetics is unrelated to antidiabetic therapy.

Atherosclerosis is a slowly progressive disorder, becoming clinically manifest with advancing years, and it would be expected that there would be a relation between the duration of diabetes and the incidence of atherosclerosis. Such a relationship has been described by some [18-21], but not all authors [22-26]. As the incidence of both glucose intolerance and arterial disease increases with advancing years, it may be age rather than duration of diabetes that is important [22].

There appears to be little [21] or no $[18,22,23]$ relationship between the frequency of the large vessel complications and the severity of diabetes, as measured by the degree of hyperglycaemia or the treatment required. Nor is the degree of 'control' of diabetes by treatment related to the occurrence of atherosclerotic heart disease [22]. Furthermore, the large prospective study organised by the University Group Diabetes Program [27] on the treatment of diabetes showed that reduction of blood glucose levels by any means was not effective in preventing fatal cardiovascular disease.

The fact that vascular disease in diabetes appears to have little relationship to the severity or duration of the disease, and is not benefitted by current therapeutic regimes, suggests that it is unlikely that hyperglycaemia is the essential factor promoting atherosclerosis in diabetics. Abnormalities of lipid metabolism, obesity and hypertension all occur in diabetics but none of these can fully explain the association of diabetes with atherosclerosis [17].

\section{Insulin}

\section{Insulin and Diabetes}

The development of sensitive radio immunoassays has clarified the abnormalities of insulin secretion in diabetes. Insulin is secreted from at least two functional pools, one of which, the slowly releasable synthesis-dependent pool, is mainly responsible for basal insulin secretion, while the rapidly releasable storage pool is responsible for the acute insulin 
response to glucose stimulation [28]. In normal subjects, basal and stimulated insulin levels are linearly related, and there is a linear relationship between relative body weight and basal insulin secretion [29].

In diabetics the relationship between basal insulin and obesity is unaltered [28]. Even when ketotic, diabetics have normal basal insulin levels. However, the acute insulin response to glucose is impaired in diabetics, whether the glucose is given orally or intravenously. Thus, if weight-matched diabetics and non-diabetics are compared, they will have equal basal (or fasting) insulin levels but the diabetics will have a lower insulin response to glucose. Obese diabetics, however, will have higher basal insulin levels and perhaps higher post-glucose levels than thin non-diabetics. As obesity is considerably more common in diabetics than in the general population [30], many diabetics will have higher circulating insulin levels than many non-diabetics.

The situation in the insulin-requiring diabetic is more complicated. The majority of insulin-treated diabetics receive considerably more than the $20-30$ units which is the daily insulin output of the normal pancreas [31]. A number of studies of insulin levels in insulin-treated diabetics have been reported, and the results have been contradictory. Some studies have shown fasting insulin levels that are normal or elevated, sometimes grossly, in insulin-treated diabetics fourteen to twenty-four hours after their last insulin injection [32-35]. Other workers have shown abnormally low fasting free insulin levels in insulin-treated diabetics [36]. Clearly the technical problems in the measurements have to be resolved before firm conclusions can be drawn on the insulin levels in insulintreated diabetics.

Not only may the fasting insulin concentrations in insulin-treated diabetics be abnormal, but normal regulation of insulin secretion is no longer present. Thus the insulin delivered from the injection site to the circulation is not related to the nutritional status of the subject, and insulin-treated diabetics will at times have insulin levels which are inappropriate for their metabolic requirements. The route of insulin administration is also abnormal in the insulin-treated diabetic. Thus the systemic circulation is first exposed to insulin, in contrast to the normal situation where the liver, the major organ for glucose homeostasis, is exposed to insulin first, and removes about 50 per cent of secreted insulin in the first passage.

Thus, whether because of therapy or because of co-existing obesity, few diabetics are truly insulindeficient, and many diabetics appear to have excessive levels of circulating insulin. Hyperinsulinaemia has also been described in mild or potential diabetics [37-40].

\section{Insulin and Hypertriglyceridaemia}

Hypertriglyceridaemia is the commonest lipid abnormality in diabetes [41]. Hypertriglyceridaemia is associated with atherosclerosis in diabetics, [41-42], and in non-diabetics it is an important risk factor for ischaemic heart disease [43].

A number of studies have reported a significant correlation between insulin levels and triglyceride levels in normal and hypertriglyceridaemic nondiabetic subjects [44]. Insulin has been shown to promote lipoprotein triglyceride synthesis in the perfused rat liver [45] and to be closely associated with triglyceride secretion rates in the obese sand rat [46]. It is likely that at least part of the hypertriglyceridaemia associated with obesity is due to high insulin levels promoting triglyceride production. The high basal insulin levels of obesity will also promote triglyceride synthesis in obese diabetics.

\section{Insulin and Atherosclerosis}

There have been only two studies of the relationship between insulin secretion and atherosclerosis in diabetes. In one [42], it was found that in patients not receiving insulin therapy, the ratios of circulating insulin to glucose levels were significantly higher in diabetics with atherosclerosis. Diabetics with atherosclerosis also had slightly higher fasting insulin levels than diabetics without atherosclerosis, but the difference was not statistically significant. In a study of glucose tolerance and insulin secretion in ischaemic heart disease [47], diabetics with atherosclerosis had slightly higher insulin responses to oral glucose, and a higher peak insulin response to oral tolbutamide than diabetics with no evidence of ischaemic heart disease.

A number of studies of insulin levels in nondiabetic subjects with atherosclerosis have also been reported. These have shown elevated insulin responses to oral glucose in subjects with disease of coronary $[47-53]$, peripheral $[14,53,54]$ and cerebral [55] arteries. There are however discrepancies in the detailed results of some of these studies. Some authors have reported elevated insulin levels only in subjects with abnormal glucose tolerance [52], whereas most others found hyperinsulinaemia in the presence of normal glucose levels. In most studies hyperinsulinaemia was found up to one year after a myocardial infarction, but one study [56] reported slightly elevated insulin levels three months after a myocardial infarction, and normal insulin levels when the subjects were retested nine months later. Contradictory findings in intravenous glucose tolerance and tolbutamide tests have been reported [49, 51, 
57]. Most studies report no difference in fasting insulin in subjects with atherosclerosis and controls, but Devlin and Stevenson [58] found that compared to age and weight-matched controls, subjects with myocardial infarction had fasting hyperinsulinaemia persisting for up to four months after the infarction. In two studies in which lipid, glucose and insulin levels were measured in subjects with ischaemic heart disease [50] or peripheral vascular disease [59], elevated insulin responses to oral glucose were the commonest abnormality. Both these studies included subjects without complete arterial occlusion or infarction, suggesting perhaps that the insulin abnormalities are associated with the arterial disease itself. There are single reports of high insulin levels in subjects with hypertension [54] and 'type A' personality traits [60], both of which may predispose to atherosclerosis.

Although there have been no prospective studies on the relationship of insulin levels to atherosclerosis, two population studies have shown high insulin responses to glucose in populations with a high incidence of ischaemic heart disease. Thus white South Africans have higher insulin responses than Bantus corresponding to the relative frequencies of atherosclerosis in these two populations [61]. Edinburgh men who have a high incidence of ischaemic heart disease have higher insulin responses to glucose than Stockholm men who have a lower incidence of this disease [62].

Several reports have appeared suggesting that hyperinsulinism may not be characteristic of atherosclerosis in diabetics or non-diabetics. In a study of diabetics who were not treated with insulin [63], it was found that there was a higher frequency of vascular complications in those with a 'poor insulin response' to oral glucose than in those with a 'moderate response'. However, the vascular complications studied included retinopathy, neuropathy and peripheral vascular disease, but not ischaemic heart disease, and thus included both microangiopathic and macroangiopathic complications. There were no details of how the two types of vascular disease were distributed between the two types of insulin responses. Furthermore, the division between moderate and poor insulin responses was based on an insulin: glucose relationship rather than on the absolute insulin levels. In twenty-three patients with peripheral vascular disease [64], the insulin response to glucose, calculated as the ratio of the peak insulin response divided by the basal level, was not elevated above normal controls, and was depressed in some patients. Actual values for the basal and stimulated insulin levels were not given, but it was stated that the patients had raised fasting insulin levels. It has been suggested [65] that the data on insulin levels in atherosclerosis can be manipulated to show an unresponsiveness of the pancreatic islets in this condition. However, it must be emphasised that when the metabolic effects of insulin are being considered, it is absolute circulating concentrations of insulin that are relevant.

The balance of evidence seems to indicate that a proportion of subjects with normal or mildly abnormal glucose tolerance and atherosclerotic vascular disease have elevated insulin responses to oral glucose. The insulin response to intravenous glucose is less certain, suggesting that the elevated response to oral glucose may be indirect, perhaps mediated by gastrointestinal hormones. The possibility that the elevated insulin levels are related to mild degrees of obesity in the atherosclerotic subjects has not been rigorously excluded.

\section{Experimental Models of Diabetes and Atherosclerosis}

Simultaneously in 1949, Duff and McMillan [66], and McGill and Holman [67] reported that rabbits with alloxan diabetes fed high cholesterol diets developed fewer vascular lesions than control animals fed the same diet, despite similar serum cholesterol levels in the two groups. Animals which were treated with alloxan but which did not develop chronic hyperglycaemia had similar vascular lesions to control animals. Later Duff et al. [68] reported that in alloxanised animals, correction of hyperglycaemia with insulin reversed the inhibition of atherogenesis. When the pancreas was temporarily excluded from the circulation during alloxan administration, the vascular disease induced by cholesterol feeding was similar to that in control animals [69]. Thus experimental ablation of insulin-secretory cells appeared to protect animals from dietinduced atherosclerosis, and vascular disease did not appear to be always an inevitable consequence of hypercholesterolaemia.

Much of the other experimental work on diabetes and arterial disease has produced confusing results because the animals have been given insulin [70,71], or the circulating lipid levels in the diabetic animals have been much higher than in the controls [71, 72]. Nevertheless, in some studies, the diabetic animals developed less, or no greater lesions than controls despite higher lipid levels $[73,74,75]$. When insulin and saline were infused respectively into the right and left femoral arteries of alloxan diabetic dogs [76], the insulin-treated artery developed intimal and medial proliferation and contained more cholesterol and fatty acids than the control artery. 
Arteries taken from animals with experimental diabetes have depressed lipid and glucose metabolism [77-80]. The artery contains a hormone-sensitive lipase whose activity is increased by experimental diabetes and lipolytic hormones such as adrenaline and glucagon and suppressed by insulin [81].

It thus appears that hyperglycaemia due to ablation or removal of insulin-secreting cells does not enhance the development of arterial lesions. It is difficult to extrapolate the results of these experiments to spontaneous diabetes in man. However, it is likely that experimental diabetes is not strictly comparable to primary idiopathic diabetes in humans, but bears a closer resemblance to diabetes secondary to pancreatic disease or pancreatectomy. In particular, the pattern of insulin secretion in experimental diabetes is different to that found in the majority of diabetics, particularly obese patients whose diabetes develops in middle age. The experiments suggest that the presence of insulin may be necessary for the development of arterial lesions.

\section{The Metabolism of the Arterial Wall in Relation to Diabetes and Insulin}

\section{The Polyol Pathway}

Polyols, or sugar alcohols, are organic compounds containing multiple alcoholic groups that are derived from sugars by the reduction of their free aldehyde or ketone groups. The polyol pathway catalyses the reduction of $\mathrm{D}$-glucose to its polyol derivative, sorbitol, and its subsequent oxidation to D-fructose. The metabolic pathway operates irreversibly in intact tissues and is not dependent on the presence of insulin. The rate of sorbitol formation increases with increasing glucose concentration over a wide range [82]. The polyol pathway has been demonstrated in the aortic intima and media of humans and rabbits [83-84]. Extracts of whole rabbit aorta, incubated in high medium glucose concentrations, showed an increased concentration of sorbitol and fructose, an increased water content, and depressed oxygen uptake. Freshly prepared aortic segments from alloxan diabetic animals also showed a greater water content and a reduced rate of respiration compared with tissue from normal controls prepared under the same conditions.

It is suggested that high ambient glucose concentrations cause an increase in the activity of the polyol pathway in the arterial wall, with intracellular accumulation of sorbitol in the wall. The osmotic activity of the sorbitol and other, as yet unidentified factors, cause an increase in the tissue water content, which impairs oxygen diffusion, resulting in a decrease in the respiratory rate. This may alter the metabolism of the arterial wall and possibly contribute towards the production of arterial lesions. However, neither cellular proliferation nor accumulation of lipid or connective tissue has been associated with the polyol pathway, and atheromatous lesions at least in experimental animals, are associated with enhanced, rather than depressed, tissue respiration [85]. Thus, although the polyol pathway provides a link between hyperglycaemia and the metabolism of the arterial wall, its role in the pathogenesis of atherosclerosis in diabetes is not yet clear.

\section{The Metabolism of Triglyceride-Rich Lipoproteins by Arterial Smooth Muscle Cells}

Although hypertriglyceridaemia appears to be closely associated with atherosclerosis in both nondiabetic and diabetic subjects, the mechanism of the association is not clear. A relationship between triglyceride levels and insulin secretion and the relevance of this to atherogenesis has already been discussed.

Studies of cultured arterial smooth muscle cells have helped to clarify the situation. Very low density lipoproteins and high density lipoproteins were taken up by cultured rat arterial smooth muscle cells [86], the uptake being linearly related to the lipoprotein concentration in the medium. The smooth muscle cells were also able to catabolise the lipoproteins, the triglyceride being hydrolysed within the smooth muscle cell while the cholesterol remained, perhaps to be linked to elastin [87]. Furthermore, very low density lipoprotein 'remnants', particles which are formed in the circulation by lipolysis of most of the lipoprotein triglyceride of very low density lipoproteins and chylomicrons by lipoprotein lipase, were avidly taken up by cultured smooth muscle cells [86]. The uptake of remnants was much more rapid than that of very low density lipoproteins.

Thus, if remnants are normally present, even transiently, during the metabolism of very low density lipoproteins, and present in increased concentrations in certain hyperlipoproteinaemic subjects, the results of these studies may provide a mechanism whereby hypertriglyceridaemia can influence the pathogenesis of atherosclerosis. A hypothesis has been presented linking atherogenesis with the action of lipoprotein lipase on triglyceriderich lipoproteins [88]. It is suggested that lipoprotein lipase located on the arterial endothelium may liberate cholesterol-rich fragments by degrading very low density lipoproteins or chylomicrons. The resulting 
high local concentrations of cholesterol-rich lipoproteins would enhance the uptake of cholesterol by the arterial intima.

\section{The Effect of Insulin on the Arterial Wall}

a) Cellular Proliferation: The development by Ross [89] of a method for growing arterial smooth muscle cells in culture has provided the means of directly studying the effect of various factors implicated in atherosclerosis. In smooth muscle cells grown from explants of thoracic aortae of one-year-old male pigtail monkeys, the addition of insulin in concentrations ranging from $10 \mu \mathrm{U}$ to $10,000 \mu \mathrm{U} / \mathrm{ml}$ resulted in progressively greater stimulation of cell proliferation [90]. Serum from which insulin had been removed stimulated growth less well than whole serum at the same concentration. The difference in the insulin concentration to which the cells were exposed in this situation was 2 to $3 \mu \mathrm{U} / \mathrm{ml}$, indicating that the cells were sensitive to very small concentrations of insulin. Cells which had been passed eight or more times, and had thus 'aged' in culture, did not proliferate in response to insulin, and showed an attenuation of the normal proliferative response to serum.

Serum from diabetic rabbits [91] and human diabetics [92] increases the outgrowth of smooth muscle cells from primary cultures of rabbit aortas. Both the animals and humans had been treated with large doses of insulin, and as it seemed that neither hyperglycaemia nor hyperlipidaemia was responsible for the cellular proliferation, it is possible that insulin was the stimulus. In later experiments it was shown that small concentrations of insulin did not, although growth hormone did, cause smooth muscle cell proliferation in this experimental system [93]. However, the insulin was added to medium containing a high concentration of serum and it is possible that the cells were already under maximal proliferative stimulation from the serum.

Other factors which stimulate proliferation of cultured arterial smooth muscle cells include a factor associated with platelets [94] and low density lipoproteins [95]. However, the relationship of these factors to atherosclerosis in diabetes is not clear.

It has been suggested that cells of patients with diabetes are excessively vulnerable to injury and death because of an inherited cellular defect [96]. This hypothesis is supported by studies on skin fibroblasts cultured from diabetics [97-99] and by studies on diabetic capillary basal lamina [100]. Studies of the cellular basis of atherosclerosis in diabetes have only just begun, but they clearly offer the hope of further understanding this disorder. b) Arterial Lipid Metabolism: Accumulation of lipid in the intima and adjacent media is one of the best known features of the atheromatous lesion. The origin of the atheromatous lipid is described in more detail elsewhere [17]. Insulin's effect on arterial wall lipid has been demonstrated in several experimental systems. The intravenous administration of insulin to normal rats resulted in enhanced synthesis of cholesterol, triglyceride and fatty acids in the aorta [101-103]. The incorporation of glucose into aortic lipid was depressed in streptozotocin-diabetic animals compared with normal controls [104]. The insulin levels at the time of sacrifice in the control and treated animals were significantly correlated with the aortic lipid metabolism, but the latter was not related to blood glucose levels. Similar results have been reported from Japan [105]. Insulin-treated chickens, fed a normal diet, developed considerably more lipid-containing lesions in their aortas than control birds [106-107]. The lesions were focal in distribution, and involved the intima, and in more severe cases, the adjacent media, and thus resembled early human fatty streak lesions.

In cultured rat arterial smooth muscle cells, insulin in physiological concentrations stimulated cholesterol synthesis from acetate [108]. No effect of insulin was found when mevalonate was the substrate, a finding which is consistent with insulin acting on the enzyme 3-hydroxy-3-methylglutaryl coenzyme A reductase. Cyclic AMP inhibited sterol synthesis in arterial smooth muscle cells [109]. Glucagon also had an inhibiting effect but only in very high concentrations [109].

It has recently been reported that insulin stimulates the binding of low density lipoprotein to cultured human fibroblasts [110]. If this effect also occurs in arterial cells it may be relevant to the accumulation of cellular cholesterol and its esterification which are characteristic features of atherosclerosis [111].

This series of experiments has shown that insulin has effects on the arterial wall which may be relevant to the pathogenesis of atherosclerosis. The results of these studies are consistent with earlier less direct evidence on the effect of insulin on arterial lipids. In non-diabetic animals, administration of insulin [112] prevented the regression of arterial lesions in chickens which normally occurs when a high cholesterol diet is replaced by a normal diet. Insulin also prevented oestrogen-induced protection of coronary atherosclerosis in cholesterol-fed cockerels [112]: The spiny mouse (Acomys cahirinus) which develops obesity, diabetes and hyperinsulinism, has been reported to develop spontaneous lesions of its coronary arteries on a normal diet [113]. 
There is thus evidence that insulin has a direct effect on the artery which may be relevant to atherogenesis. Insulin also has an important role in the regulation of plasma lipid transport. The importance of insulin-mediated changes in lipid metabolism in the development of atherosclerosis in both diabetics and non-diabetics remains to be elucidated $[114,115]$.

\section{Conclusions - A Hypothesis}

The high frequency of atherosclerosis and its complications in the presence of hyperglycaemia and diabetes is now well established. The risk of hyperglycaemia is associated with the arterial disease itself, as well as with its complications. While the presence of hyperlipidaemia or hypertension in the diabetic will contribute to the development of the vascular disease, epidemiological studies indicate that there is an additional factor associated with diabetes itself.

There is little evidence that hyperglycaemia directly contributes to the development of atherosclerosis. The generally reported lack of relationship between the severity of diabetes and the vascular complications, and the lack of benefit from regimes designed to lower the blood sugar, suggest that hyperglycaemia is not the factor linking diabetes with atherosclerosis. It must be recognised however that 'good control', as normally defined, is a condition far different from the normal physiology of carbohydrate

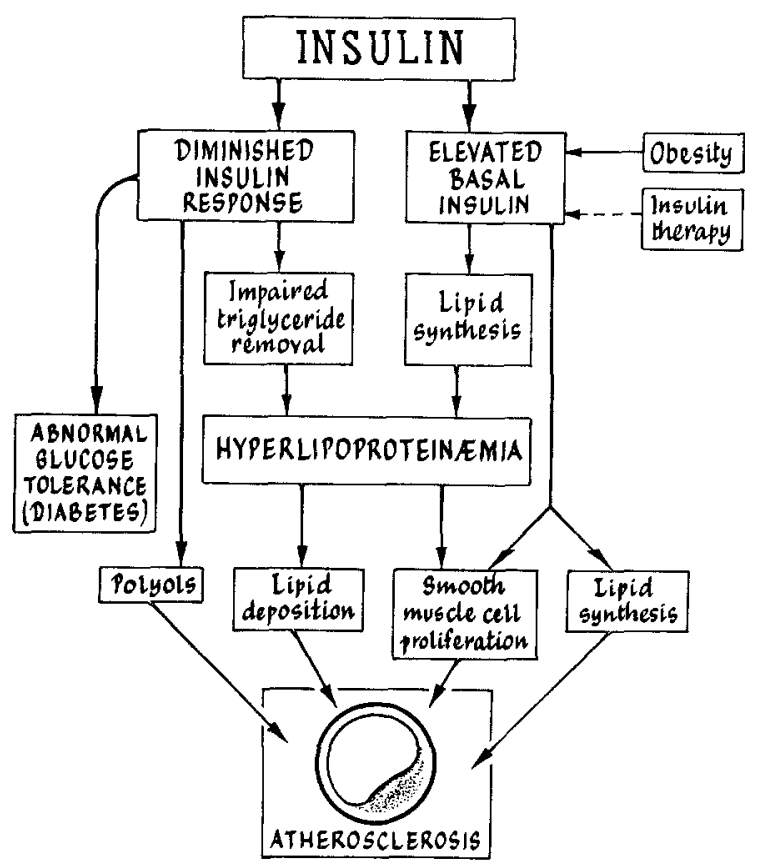

Fig. 1. Diagram indicating how abnormal insulin concentrations may contribute to the development of atherosclerosis (modified from Bierman [117]) metabolism. There are probably several factors that contribute to the development of atherosclerosis in diabetes, but whether these factors are an inherent part of the diabetic syndrome, or are environmental is not clear. The fact that diabetics can survive with their disease for long periods without developing vascular disease [114], and that a low incidence of atherosclerosis is found in diabetics in some parts of the world [6] suggests that environmental factors are important.

The frequency of atherosclerosis as a complication of diabetes has become progressively more important in the years since insulin became available for the treatment of diabetes. This has been attributed to the decreasing importance of other complications such as ketoacidosis and infection, and the resulting greater life expectancy of diabetics. The possibility that diabetic treatment may have directly contributed to the development of the vascular complications has been little considered. The results of the UGPD study and, to some extent, the data from Framingham [4] raise this possibility.

For most of the last half century, few diabetics have been truly insulin-deficient. The majority of diabetics are overweight and have high basal insulin levels, although their response to an acute glucose challenge is impaired. Diabetics who require treatment with insulin usually receive doses far in excess of the normal daily output of insulin from the pancreas. In addition, the circulating exogenous insulin concentration is often inappropriate to the nutritional status of the subject, and the injected insulin first passes through the systemic circulation, instead of through the portal circulation and the liver as with normal insulin secretion.

The possibility that insulin may contribute to the development of the large vessel complications of diabetics has been explored, and evidence has been presented that insulin stimulates arterial smooth muscle cell proliferation and lipid synthesis in the arterial wall. A scheme can be devised (Figure) linking insulin with atherosclerosis either by a direct effect on the artery, or by way of its effect on lipid metabolism. While most of the pathways in this diagram have been demonstrated to exist, the relationship of the whole scheme to the development of atherosclerosis in diabetes remains hypothetical. It does however suggest several lines along which future research might be pursued.

\section{References}

1. Strandness, D. W., Priest, R. W., Gibbons, G. E.: Combined clinical and pathologic study of diabetic and nondiabetic peripheral arterial disease. Diabetes 13, 336-372 (1964) 
2. Epstein, F. H.: Hyperglycemia. A risk factor in coronary heart disease. Circulation 36, 609-619 (1967)

3. Mainland, D.: The risk of fallacious conclusions from autopsy data on the incidence of disease with applications to heart disease. Am. Heart J. 45, 644-654 (1953)

4. Garcia, M. J., McNamara, P. M., Gordon, T., Kannel, W. B.: Morbidity and mortality in diabetics in the Framingham population. Sixteen year follow-up study. Diabetes 23, 105-111 (1974)

5. Gordon, T., Castelli, W. P., Hjortland, M. C., Kannel, W. B., Dawber, T. R.: Diabetes, blood lipids, and the role of obesity in coronary heart disease risk for women. The Framingham Study. Ann. Intern. Med. 87, 393-397 (1977)

6. Keen, H., Jarrett, R. J.: Macroangiopathy - its prevalence in asymptomatic diabetes. Adv. Metab. Disord. [Suppl.] 2, 3-9 (1973)

7. Ostrander, L. D., Francis, T., Hayner, N. S., Kjelsberg, M.O., Epstein, F.H.: The relationship of cardio-vascular disease to hyperglycemia. Ann. Intern. Med. 62, 1188-1198 (1965)

8. Epstein, F.H., Ostrander, L. D., Johnson, B. J., Payne, M. W., Hayner, N. S., Keller, J. B., Francis, T.: Epidemiological studies of cardiovascular disease in a total community Tecumseh, Michigan. Ann. Intern. Med. 62, 1170-1187 (1965)

9. Pell, S., D'Alonzo, C. A.: Factors associated with long-term survival of diabetes. J. A. M. A. 214, 1833-1840 (1970)

10. Wahlberg, F., Thomasson, B.: Glucose tolerance in ischaemic cardiovascular disease. In: Carbohydrate metabolism and its disorders. Dickens, F., Randle, P. J., Whelen, W. J. (Eds.); pp. 185-198. London: Academic Press 1968

11. Heinle, R. A., Levy, R. I., Frederickson, D. S., Gorlin, R.: Lipid and carbohydrate abnormalities in patients with angiographically documented coronary artery disease, Am. J. Cardiol. 24, 178-186 (1969)

12. Falsetti, H. L., Schnatz, J. D., Greene, D. G., Bunnell, I. L.: Serum lipids and glucose tolerance in angiographically proved coronary artery disease. Chest 58, 111-115 (1970)

13. Kingsbury, K. J.: The relation between glucose tolerance and atherosclerotic vascular disease. Lancet 1966 II, 1374-1379

14. Sloan, J. M., Mackay, J. S., Sheridan, B.: Glucose tolerance and insulin response in atherosclerosis. Br. Med. J. 1970 IV, $586-588$

15. Ingelfinger, J. A., Bennet, P. H., Liebow, I. M., Miller, M.: Coronary heart disease in the Pima Indians. Electrocardiographic findings and postmortem evidence of myocardial infarction in a population with a high prevalence of diabetes mellitus. Diabetes 25, 561-565 (1976)

16. Merimee, T.J.: A follow-up study of vascular disease in growth-hormone-deficient dwarfs with diabetes. N. Engl. J. Med. 298, 1217-1222 (1978)

17. Stout, R. W., Bierman, E. L., Brunzell, J. D.: Atherosclerosis and disorders of lipid metabolism in diabetes. In: Physiological and biochemical basis of diabetes. Vallence-Owen, J. (Ed.), pp. 125-170. Lancaster: M. T. P. 1975

18. Stearns, S., Schlesinger, M. J., Rudy, A.: Incidence and clinical significance of coronary artery disease in diabetes mellitus. Arch. Intern. Med. 80, 463-474 (1947)

19. Ricketts, H. T.: The problem of degenerative vascular disease in diabetes. Am. J. Med. 19, 933-945 (1955)

20. Bradley, R. F., Bryfogle, J. W.: Survival of diabetic patients after myocardial infarction. Am. J. Med. 20, 207-216 (1956)

21. Breithaupt, D. J., Leckie, R. B.: Diabetes mellitus: a study of the practicability of life insurance. Can. Med. Assoc. J. 85, 299-302 (1961)

22. Liebow, I. M., Hellerstein, H. K., Miller, M.: Arteriosclerotic heart disease in diabetes mellitus. Am. J. Med. 18, 438-447 (1955)
23. Downie, E., Martin, F. I. R.: Vascular disease in juvenile diabetic patients of long duration. Diabetes 8, 383-387 (1959)

24. New, M. I., Roberts, T. N., Bierman, E. L., Reader, G. G.: The significance of blood lipid alterations in diabetes mellitus. Diabetes 12, 208-212 (1963)

25. Reinheimer, W., Bliffen, G., McCoy, J., Wallace, D., Albrink, M. J.: Weight gain, serum lipids and vascular disease in diabetes. Am. J. Clin. Nutr. 20, 986-996 (1967)

26. Pyke, D. A.: Coronary disease and diabetes. Postgrad. Med. J. 44, 966-968 (1968)

27. University Group Diabetes Program: A study of the effects of hypoglycemic agents on the vascular complications of patients with adult-onset diabetes. Diabetes 19 [Suppl. 2], 747-830 (1970)

28. Porte, D., Jr., Bagdade, J.: Human insulin secretion: an integrated approach. Annu. Rev. Med. 21, 219-240 (1970)

29. Bagdade, J. D., Bierman, E. L., Porte, D. Jr.: The significance of basal insulin levels in evaluation of the insulin response to glucose in diabetic and non-diabetic subjects. $J$. Clin. Invest. 46, 1549-1557 (1967)

30. Pyke, D. A., Please, N. W.: Obesity, parity and diabetes. J. Endocrinol. 15, 26-33 (1957)

31. Goodner, C. J., Porte, D. Jr.: Determinants of basal insulin secretion in man. In: Handbook of physiology, Section 7, Part 1, pp. 597-609. Washington DC: American Physiological Society 1972

32. Grodsky, G. M.: Production of autoantibodies to insulin in man and rabbits. Diabetes 14, 396-403 (1965)

33. Pearson, M.J., Martin, F.I. R.: The separation of total plasma insulin from binding proteins using gel filtration: its application to the measurement of rate of insulin disappearance. Diabetologia 6, 581-585 (1970)

34. Heding, L. G.: Determination of total serum insulin (IRI) in insulin-treated diabetic patients. Diabetologia 8, 260-266 (1972)

35. Gennaro, W. D., Van Norman, J. D.: Quantitation of free, total, and antibody-bound insulin in insulin-treated diabetics. Clin. Chem. 21, 873-879 (1975)

36. Nakagawa, S., Nakayama, H., Sasaki, T., Yoshino, K., Yu, Y. Y., Shinozaki, K., Aoki, S., Mashimo, K.: A simple method for the determination of serum free insulin levels in insulin-treated patients. Diabetes 22, 590-600 (1973)

37. Danowski, T. S., Lombardo, Y. B., Mendelsohn, L. V., Corredor, D. G., Morgan, C. R., Sabeh, G.: Insulin patterns prior to and after onset of diabetes. Metabolism 18, 731-740 (1969)

38. Jackson, W. P. U., van Mieghem, W., Keller, P.: Insulin excess as the initial lesion in diabetes. Lancet 1972 I, 1040-1043

39. Reaven, G. M., Olefsky, J., Farquhar, J. W.: Does hyperglycaemia or hyperinsulinaemia characterise the patient with chemical diabetes. Lancet 1972 I, 1247-1249

40. Savage, P. J., Dippe, S. E., Bennett, P. H., Gordon, P., Roth, J., Rushforth, N. B., Miller, M.: Hyperinsulinemia and hypoinsulinemia. Insulin responses to oral carbohydrate over a wide spectrum of glucose tolerance. Diabetes 24, 363-368 (1975)

41. Ostrander, L. D., Neff, B. J., Block, W. D., Francis, T., Epstein, F. H.: Hyperglycemia and hypertriglyceridemia among persons with coronary heart disease. Ann. Intern. Med. 67, 34-41 (1967)

42. Santen, R. J., Willis, P. W., Fajans, S. S.: Atherosclerosis in diabetes mellitus. Arch. Intern. Med. 130, 833-843 (1972)

43. Carlson, L. A., Bottiger, L. E.: Ischaemic heart disease in relation to fasting values of plasma triglycerides and cholesterol. Lancet 1972 I, 865-868

44. Bierman, E. L., Porte, D. Jr., Bagdade, J. D.: Hypertriglyceridemia and glucose intolerance in man. In: Adipose tissue. 
Jeanrenaud, B., Hepp, D. (Eds.), pp. 209-212. New York: Academic Press 1970

45. Topping, D. L., Mayes, P. A.: The immediate effects of insulin and fructose on the metabolism of the perfused liver: changes in lipoprotein secretion, fatty acid oxidation and esterification, lipogenesis and carbohydrate metabolism. Biochem. J. 126, 295-311 (1972)

46. Robertson, R. P., Gavareski, D. J., Henderson, J. D., Porte, D., Jr., Bierman, E. L.: Accelerated triglyceride secretion. A metabolic consequence of obesity. J. Clin. Invest. 52, 1620-1626 (1973)

47. Kashyap, L., Magill, F., Rojas, L., Hoffman, M. M.: Insulin and non-esterified fatty acid metabolism in asymptomatic diabetics and atherosclerotic subjects. Can. Med. Assoc. J. 102, 1165-1169 (1970)

48. Peters, N., Hales, C. N.: Plasma insulin concentrations after myocardial infarction. Lancet 1965 I, 1144-1145

49. Nikkila, E. A., Miettinen, T. A., Vesenne, M. R., Pelkonen, R.: Plasma insulin in coronary heart disease. Lancet $1965 \mathrm{I}$, 508-511

50. Tzagournis, M., Chiles, R., Ryan, J. M., Skillman, T. G.: Interrelationships of hyperinsulinism and hypertriglyceridemia in young patients in coronary heart disease. Circulation $\mathbf{3 8}$, 1156-1163 (1968)

51. Malherbe, C., de Gasparo, M., Berthet, P., de Hertogh, R., Hoet, J. J.: The pattern of plasma insulin response to glucose in patients with a previous myocardial infarction - the respective effects of age and disease. Eur. J. Clin. Invest. 1, 265-270 (1970)

52. Gertler, M. M., Leetma, H. E., Saluste, E., Rosenberger, J. L., Guthrie, R. G.: Ischemic heart disease. Insulin, carbohydrate and lipid interrelationships. Circulation 46, 103-111 (1972)

53. Sorge, F., Schwartkopff, W., Neuhaus, G. U.: Insulin response to oral glucose in patients with a previous myocardial infarction and in patients with peripheral vascular disease. Diabetes 25, 586-594 (1976)

54. Welborn, T. A., Breckenridge, A., Rubenstein, A. H., Dollery, C. T., Fraser, T. R.: Serum-insulin in essential hypertension and in peripheral vascular disease. Lancet 1966 I, 1336-1337

55. Gertler, M. M., Leetma, H. E., Saluste, E., Covalt, D. A., Rosenberger, J.L.: Covert diabetes mellitus in ischaemic heart and cerebrovascular disease. Geriatrics 27, 105-120 (1972)

56. Berchtold, P., Bjorntorp, P., Gustafson, A., Lindholm, B., Tiblin, T., Wilhalmsen, L.: Glucose tolerance, plasma insulin and lipids in relation to adipose tissue cellularity in men after myocardial infarction. Acta Med. Scand. 191, 35-41 (1972)

57. Christiansen, I., Deckert, T., Kjerulf, K., Mitgaard, K., Worning, $H_{\text {.: }}$ Glucose tolerance, plasma lipids and serum insulin in patients with ischaemic heart disease. Acta Med. Scand. 184, 283-287 (1968)

58. Devlin, J. G., Stephenson, N.: Hyperinsulinism and hypoglycaemia following acute myocardial infarction. Metabolism 17, 999-1004 (1968)

59. Sloan, J. M., Mackay, J. S., Sheridan, B.: The incidence of plasma insulin, blood sugar and serum lipid abnormalities in patients with atherosclerotic disease. Diabetologia 7, 431-433 (1971)

60. Friedman, M., Byers, S. O., Roseman, R. H., Elevitch, F. R.: Coronary-prone individuals (type A behaviour pattern). Some biochemical characteristics. J.A.M.A. 212, 1030-1037 (1970)

61. Rubenstein, A.H., Seftel, H.C., Miller, K., Bersohn, I., Wright, A. D.: Metabolic responses to oral glucose in healthy South African white, Indian, and African subjects. Br. Med. J. 1969 I, $748-751$
62. Logan, R. L., Thomson, M., Riemersma, R. A., Oliver, M. F., Olsson, A. G., Rossner, S., Callmer, E., Walldius, G., Kaijser, L., Carlson, L. A., Lockerbie, L., Lutz, W.: Risk factors for ischaemic heart-disease in normal men aged 40 (Edinburgh-Stockholm study). Lancet 1978 I, 949-955

63. Elkeles, R. S., Lowy, C., Wyllie, A. D. H., Young, J. L., Fraser, T. R.: Serum insulin, glucose and lipid levels among mild diabetics in relation to incidence of vascular complications. Lancet 1971 I, 880-883

64. Ghilchik, M. W., Morris, A. S.: Insulin response to glucose in patients with peripheral vascular disease, arteritis, and Raynaud's phenomenon. Lancet 1971 II, 1229-1231

65. Luft, R., Efendic, S., Cerasi, E.: Prediabetes, diabetes and arteriosclerosis. In: Early phases of coronary heart disease. Larsson, T., Ljungstedt, N. (Eds.), pp. 223-232. Stockholm: Nordiska 1973

66. Duff, G. L., McMillan, G. C.: The effect of alloxan diabetes on experimental atherosclerosis in the rabbit. I. The inhibition of experimental atherosclerosis in alloxan diabetes. II. The effect of alloxan diabetes on the retrogression of experimental cholesterol atherosclerosis. J. Exp. Med. 89, 611-630 (1949)

67. McGill, H. C., Holman, R. L.: The influence of alloxan diabetes on cholesterol atheromatosis in the rabbit. Proc. Soc. Exp. Biol. Med. 72, 72-75 (1949)

68. Duff, G. L., Brechin, J. H., Finkelstein, W. E.: The effect of alloxan diabetes on experimental cholesterol atherosclerosis in the rabbit. IV The effect of insulin therapy on the inhibition of atherosclerosis in the alloxan-diabetic rabbit. J. Exp. Med. 100, 371-380 (1954)

69. Cook, D. L., Mills, L. M., Green, O. M.: The mechanism of alloxan protection in experimental atherosclerosis. J. Exp. Med. 99, 119-124 (1954)

70. Beveridge, J. M. R., Johnson, S. E.: Studies on diabetic rats; the production of cardiovascular and renal disease in diabetic rats. Br. J. Exp. Pathol. 31, 285-293 (1950)

71. Lehner, N. D. M., Clarkson, T. B., Lofland, H. B.: The effect of insulin deficiency, hypothyroidism, and hypertension on atherosclerosis in the squirrel monkey. Exp. Mol. Pathol. 15, 230-244 (1971)

72. Kalant, N., Teitelbaum, J. I., Cooperberg, A. A., Harland, W. A.: Dietary atherogenesis in alloxan diabetes. J. Lab. Clin. Med. 63, 147-157 (1964)

73. Pierce, F. T.: The relationship of serum lipoproteins to atherosclerosis in the cholesterol-fed alloxanized rabbit. Circulation 5, 401-407 (1952)

74. Kalant, N., Harland, W. A.: The effect of an atherogenic diet on normal and alloxan-diabetic rats. Can. Med. Assoc. J. 84, 251-254 (1961)

75. Wilson, R. B., Martin, J. M., Hartroft, W. S.: Failure of insulin therapy to prevent cardiovascular lesions in diabetic rats fed an atherogenic diet. Diabetes 18, 225-231 (1969)

76. Cruz, A. B., Amatuzio, D. S., Grande, F., Hay, L. J.: Effect of intra-arterial insulin on tissue cholesterol and fatty acids in alloxan-diabetic dogs. Circ. Res. 9, 39-43 (1961)

77. Foster, D. W., Siperstein, M. D.: Effect of diabetes on cholesterol and fatty acid synthesis in the rat aorta. Am. J. Physiol. 198, 25-28 (1960)

78. Wertheimer, H. E., Bentor, V.: Influence of diabetes on carcohydrate metabolism of aortic tissue. Diabetes 11, 422-425 (1962)

79. Mulcahy, P. D., Winegrad, A. I.: Effects of insulin and alloxan diabetes on glucose metabolism in rabbit aortic tissue. Am. J. Physiol. 203, 1038-1042 (1962)

80. Urrutia, G., Beavan, D. W., Cahill, G. F.: Metabolism of glucose-U-C $\mathrm{C}^{14}$ in rat aorta in vitro. Metabolism 11, 530-534 (1962)

81. Mahler, R. F.: Diabetes and arterial lipids. Q. J. Med. 34, 484-485 (1965) 
82. Gabbay, K. H.: The sorbitol pathway and the complications of diabetes. N. Engl. J. Med. 288, 831-836 (1973)

83. Clements, R. S., Jr., Morrison, A. D., Winegrad, A. I.: Polyol pathway in aorta: regulation by hormones. Science 166 , 1007-1008 (1969)

84. Morrison, A. D., Clements, R. S., Winegrad, A. I.: Effects of elevated glucose concentrations on the metabolism of the aortic wall. J. Clin. Invest. 51, 3114-3123 (1972)

85. Whereat, A. E.: Atherosclerosis and metabolic disorder of the arterial wall. Exp. Mol. Pathol. 7, 233-247 (1967)

86. Bierman, E. L., Eisenberg, S., Stein, O., Stein, Y.: Very low density lipoprotein 'remnant' particles: uptake by aortic smooth muscle cells in culture. Biochim. Biophys. Acta 329, 163-169 (1973)

87. Kramsch, D. M., Hollander, W.: The interaction of serum and arterial lipoproteins with elastin of the arterial intima and its role in the lipid accumulation in atherosclerotic plaques. J. Clin. Invest. 52, 236-247 (1973)

88. Zilversmit, D. B.: A proposal linking atherogenesis to the interaction of endothelial lipoprotein lipase with triglyceriderich lipoproteins. Circ. Res. 33, 633-638 (1973)

89. Ross, R.: The smooth muscle cell. II Growth of smooth muscle in culture and formation of elastic fibres. J. Cell Biol. 50, 172-186 (1971)

90. Stout, R. W., Bierman, E. L., Ross, R.: The effect of insulin on the proliferation of cultured primate arterial smooth muscle cells. Circ. Res. 36, 319-327 (1975)

91. Ledet, T., Dzoga, K. F., Wissler, R.W.: Growth of rabbit aortic smooth-muscle cells cultured in media containing diabetic and hyperlipemic serum. Diabetes 25, 207-215 (1976)

92. Ledet, T.: Growth of rabbit aortic smooth muscle cells in serum from patients with juvenile diabetes. Acta Pathol. Microbiol. Scand. [A] 84, 508-516 (1976)

93. Ledet, T.: Growth hormone stimulating the growth of arterial medial cells in vitro. Diabetes 25, 1011-1017 (1976)

94. Ross, R., Glomset, J. A., Kariya, B., Harker, L.: A plateletdependent serum factor that stimulates the proliferation of arterial smooth muscle cells in vitro. Proc. Natl. Acad. Sci. USA 71, 1207-1210 (1974)

95. Ross, R., Glomset, J.A.: Atherosclerosis and the smooth muscle cell. Science 180, 1332-1339 (1973)

96. Vracko, R., Benditt, E. P.: Manifestations of diabetes mellitus - their possible relationships to an underlying cell defect. Am. J. Pathol. 75, 204-222 (1974)

97. Goldstein, S., Littlefield, J. W., Soeldner, J. S.: Diabetes mellitus and aging: diminished plating efficiency of cultured human fibroblasts. Proc. Natl. Acad. Sci. USA 64, 155-160 (1969)

98. Martin, G. M., Sprague, C. A., Epstein, C. J.: Replicative life-span of cultivated human cells. Effects of donor's age, tissue and genotype. Lab. Invest. 23, 86-92 (1970)

99. Goldstein, S., Moerman, E. J., Soeldner, J.S., Gleason, R. E., Barnett, D. M.: Chronologic and physiologic age affect replicative life-span of fibroblasts from diabetic, prediabetic, and normal donors. Science 199, 781-782 (1978)

100. Vracko, R.: Basal lamina layering in diabetes mellitus: evidence for accelerated rate of cell death and cell regeneration. Diabetes 23, 94-104 (1974)

101. Stout, R. W.: Insulin stimulation of cholesterol synthesis by arterial tissue. Lancet 1969 II, 467-468
102. Stout, R. W.: The effect of insulin on the incorporation of (1$\left.{ }^{14} \mathrm{C}\right)$ sodium acetate into the lipids of the rat aorta. Diabetologia 7, 367-372 (1971)

103. Stout, R. W.: The effect of insulin on the incorporation of Dglucose-U $-{ }^{14} \mathrm{C}$ in the lipids of the rat aorta in vivo. Horm. Metab. Res. 7, 31-34 (1975)

104. Stout, R. W., Buchanan, K. D., Vallance-Owen, J.: Arterial lipid metabolism in relation to blood glucose and plasma insulin in rats with streptozotocin-induced diabetes. Diabetologia 8, 398-401 (1972)

105. Orimo, H., Sakurada, T., Ito, H., Okabe, H., Noma, A., Murakami, M.: Lipid metabolism in aorta of rats with streptozotocin-induced diabetes. Artery 1, 335 (1975)

106. Stout, R. W.: Development of vascular lesions in insulintreated animals fed a normal diet. Br. Med. J. 1970 III, 685-687

107. Stout, R. W., Buchanan, K. D., Vallance-Owen, J.: The relationship of arterial disease and glucagon metabolism in insulin-treated chickens. Atherosclerosis 18, 153-162 (1973)

108. Stout, R. W.: The effect of insulin and glucose on sterol synthesis in cultured rat arterial smooth muscle cells. Atherosclerosis 27, 271-278 (1977)

109. Stout, R. W.: Relative insensitivity to glucagon of sterol synthesis in cultured rat aortic smooth muscle cells. Effect of dibutyryl cyclic AMP. Diabetologia 15, 323-326 (1978)

110. Chait, A., Bierman, E. L., Albers, J. J.: Regulatory role of insulin in the degradation of low density lipoprotein by cultured human skin fibroblasts. Biochim. Biophys. Acta 529, 292-299 (1978)

111. Goldstein, J. L., Brown, M. S.: Lipoprotein receptors, cholesterol metabolism, and atherosclerosis. Arch. Pathol. Lab. Med. 99, 181-184 (1975)

112. Stamler, J., Pick, R., Katz, L. N.: Effect of insulin in the induction and regression of atherosclerosis in the chick. Circ. Res. 8, 572-576 (1960)

113. Renold, A. E., Genet, A. E., Stauffacher, W., Jeanrenaud, B.: Laboratory animals with spontaneous diabetes and/or obesity: suggested suitability for the study of spontaneous atherosclerosis. Prog. Biochem. Pharmacol. 4, 363-369 (1968)

114. Stout, R. W., Vallance-Owen, J.: Insulin and atheroma. Lancet $1969 \mathrm{I}, 1 \mathrm{O} 78-1080$

115. Stout, R. W.: The relationship of abnormal circulating insulin levels to atherosclerosis. Atherosclerosis 27, 1-13 (1977)

116. Oakley, W. G., Pyke, D. A., Tattersall, R. B., Watkins, P. J.: Long-term diabetes. Q. J. Med. NS 43, 145-156 (1974)

117. Bierman, E. L.: Hypertriglyceridemia in early diabetes. Adv. Metab. Disord. [Suppl. 2], 67-72 (1973)

Received: October 13, 1978

Prof. R. W. Stout

The Queen's University of Belfast

Department of Geriatric Medicine

Whitle Medical Building

97 Lisburn Road

Belfast BT9 $7 \mathrm{BL}$

Northern Ireland 